\title{
An ex vivo model for functional studies of myofibroblasts
}

\author{
Witold W Kilarski ${ }^{1}$, Natalia Jura ${ }^{1}$ and Pär Gerwins ${ }^{1,2}$ \\ ${ }^{1}$ Department of Genetics and Pathology, Vascular Biology Unit, The Rudbeck Laboratory, Uppsala University, \\ Uppsala, Sweden and ${ }^{2}$ Department of Oncology, Radiology, and Clinical Immunology, Section for Radiology, \\ Uppsala University Hospital, Uppsala, Sweden
}

\begin{abstract}
Migration, proliferation and invasive growth of myofibroblasts are key cellular events during formation of granulation tissue in situations of wound healing, arteriosclerosis and tumor growth. To study the invasive phenotype of myofibroblasts, we established an assay where arterial tissue from chicken embryos was embedded in fibrin gels and stimulated with growth factors. Addition of serum, PDGF-BB and FGF-2, but not VEGF-A, resulted in an outgrowth of cellular sprouts with a pattern that was similar to the organization of cells invading a provisional matrix in an in vivo model of wound healing using the chicken chorioallantoic membrane. Sprouting cells were defined as myofibroblasts based on being $\alpha$-smooth muscle actin-positive but desmin-negative. There was no contribution of endothelial cells in outgrowing sprouts. The acquired myofibroblastic phenotype was stable since sprout-derived cells resumed sprouting in a growth factorindependent manner when re-embedded as spheroids in a fibrin matrix. Invasive growth and sprouting of vascular smooth muscle cells was not limited to chicken cells since a similar response was seen when spheroids composed of purified primary human aortic smooth muscle cells were embedded in fibrin. Finally, a technique for flat visualization of the three-dimensional sprouting and a quantification method is described. This ex vivo model allows quantitative analysis of invasive growth and differentiation of vascular smooth muscle cells and fibroblasts into myofibroblasts.
\end{abstract}

Laboratory Investigation (2005) 85, 643-654, advance online publication, 21 February 2005; doi:10.1038/labinvest.3700255

Keywords: myofibroblast; smooth muscle; aorta; endothelial; sprouting; angiogenesis; growth factor

Myofibroblasts are important components during the repair of injured tissue and appear in the wound when the initial inflammatory reaction has ceased. They invade the fibrin cloth, deposit new interstitial matrix and form interconnecting contractile units responsible for wound closure. ${ }^{1}$ In most organs, tissue injury activates local fibrocytes that in the presence of macrophage-derived growth factors differentiate into contractile myofibroblasts, which are characterized by expression of $\alpha$-smooth muscle actin ( $\alpha \mathrm{SMA})$ in their mature state and a spindle-like cell shape. ${ }^{2,3}$ When injuries occur at locations where fibrocytes do not reside, like in the arterial wall or in the cornea, myofibroblasts are recruited from adjacent vascular smooth muscle cells (VSMCs) ${ }^{4}$ or keratocytes, ${ }^{5}$ respectively. Myofibroblasts are also found in pathological conditions characterized by

Correspondence: Dr P Gerwins, MD, PhD, Department of Genetics and Pathology, Vascular Biology Unit, The Rudbeck Laboratory, Uppsala University, S-751 85 Uppsala, Sweden.

E-mail: Par.Gerwins@genpat.uu.se

Received 15 October 2004; revised 12 January 2005; accepted 17 January 2005; published online 21 February 2005 fibrosis $^{3}$ and arteriosclerosis ${ }^{6}$ and during tumor invasion and growth. ${ }^{7}$ Since $\alpha$ SMA-positive contractile cells are associated with both physiological and pathological tissue remodeling, they represent potential targets for therapeutic interventions.

In vitro studies of myofibroblast functions have been primarily focused on their contractile phenotype. ${ }^{2}$ The present report describes an ex vivo assay that allows analysis of the organized invasive growth of myofibroblasts from aortic explants, which is a tissue rich in fibrocytes and VSMCs. From a practical point of view, the use of chicken embryos avoids ethical issues associated with experiments on mammals. In addition, the incubation of fertilized eggs can be performed in any laboratory using standard cell culture equipment.

\section{Materials and methods}

Induced Formation of Granulation Tissue on the Chicken Chorioallantoic Membrane

The assay was performed as described ${ }^{8}$ with minor modifications. Briefly, a window in the shell of a 
white Leghorn egg was cut on day 0 of embryo incubation and eggs were incubated in a humidified atmosphere at $38^{\circ} \mathrm{C}$. A provisional matrix consisting of $10 \mathrm{mg} / \mathrm{ml}$ fibrinogen, $3 \mathrm{mg} / \mathrm{ml}$ rat tail collagen I, $2 \mathrm{IU} / \mathrm{ml}$ thrombin, $100 \mu \mathrm{g} / \mathrm{ml}$ streptomycin, $100 \mathrm{IU} /$ $\mathrm{ml}$ penicillin, $250 \mathrm{ng} / \mathrm{ml}$ amphotericin $\mathrm{B}, 4 \mu \mathrm{g} / \mathrm{ml}$ FGF-2, and $10000 \mathrm{IU} / \mathrm{ml}$ aprotinin (pH 7.5) was prepared and $100 \mu \mathrm{l}$ of the solution applied into a $0.5-\mathrm{cm}$-high plastic tube glued on a $1.5 \times 1.5 \mathrm{~cm}$ piece of a nylon mesh (mesh size of $28 \mu \mathrm{m}$ ). The gel was allowed to polymerize overnight at $37^{\circ} \mathrm{C}$ in a humidified atmosphere. The plastic tube was removed, leaving the fibrin/collagen gel on the nylon mesh and the construct was then placed on the chicken chorioallantoic membrane (CAM) at day 13 of embryo development and eggs were incubated for another 6 days. The entire eggs were then fixed in Zn-fixative $^{9}$ and the constructs cut out from the CAM. Gels were then removed from the nylon mesh, postfixed in Zn-fixative and processed for immunohistochemistry.

\section{Visualization of Vascular Networks}

The method used is based on an article published by Paschold. ${ }^{10}$ Fertilized white Leghorn eggs were incubated in a humidified atmosphere at $38^{\circ} \mathrm{C}$ for 15 days. An embryonic chorioallantoic vessel was injected with $0.5 \mathrm{ml}$ of India ink through an opening in the eggshell and various organs were then isolated by dissection. The organs were dehydrated in a series of graded ethanol and made transparent by clarification in benzyl benzoate/benzyl alcohol (BBBA).

\section{Embedding of Arterial Tissue in Fibrin Gels}

Explants of chicken aorta were embedded in fibrin gels essentially as described. ${ }^{11}$ Chicken embryos, 15 days old, were killed and their hearts with the five main arteries removed (Figure 2e). The arteries were cleaned of connective tissue and the tunica adventitia by dissection. Residual blood was removed by cutting vessels longitudinally and washing for $2 \mathrm{~h}$ in ice-cold PBS. Fibrin gels were prepolymerized in wells of a 24-well plate by mixing thrombin (0.8 U/ $\mathrm{ml}$ final concentration) with $0.4 \mathrm{ml}$ of an ice-cold fibrinogen solution $(2.5 \mathrm{mg} / \mathrm{ml}$ fibrinogen, $100 \mu \mathrm{g} / \mathrm{ml}$ streptomycin, $100 \mathrm{U} / \mathrm{ml}$ penicillin, $250 \mathrm{ng} / \mathrm{ml} \mathrm{am-}$ photericin B, $25 \mathrm{mM}$ HEPES pH 7.0, $200 \mathrm{U} / \mathrm{ml}$ aprotinin) in Ham's F12 medium. Polymerization continued for $1 \mathrm{~h}$ at $37^{\circ} \mathrm{C}$ and plates were then chilled on ice. Approximately 3-mm-long aortic tissue pieces were placed in ice-cold fibrinogen solution and $0.5 \mathrm{ml}$ of this solution containing one aortic piece transferred into one of the wells with a prepolymerized fibrin gel. The thrombin in the prepolymerized gel diffused into the top fibrinogen layer and induced fibrin polymerization during $3 \mathrm{~h}$ of incubation at $37^{\circ} \mathrm{C}$. A volume of $1 \mathrm{ml}$ of Ham's F12 medium supplemented with $0.25 \%$ BSA, $100 \mu \mathrm{g} / \mathrm{ml}$ streptomycin, $100 \mathrm{IU} / \mathrm{ml}$ penicillin and $250 \mathrm{ng} / \mathrm{ml}$ amphotericin B was applied on top of the polymerized second gel layer and the medium was changed every 2 days. Where indicated, the medium was supplemented with one of the following growth factors: $20 \mathrm{ng} / \mathrm{ml}$ FGF-2, $20 \mathrm{ng} / \mathrm{ml}$ PDGF-BB or $200 \mathrm{ng} / \mathrm{ml}$ VEGF-A. In experiments where cells were isolated from sprouts, we first stimulated aortic explants with FGF-2 for 7 days and then removed the tissue explants with forceps. The remaining gels with sprouts were trypsinized and cells isolated and cultured on gelatin-coated dishes in Ham's F12 media with 10\% FCS. Confluent cell cultures were harvested and either plated on glass slides for immunocytochemistry (a), mixed with methylcellulose to form spheroid bodies (b) or cultured on gelatin-coated plates for immunoblotting (c).

\section{(a) Immunocytochemistry}

Cells were plated on glass slides and cultured for 2 days in Ham's F12 medium with 10\% FCS and then fixed in a Zn-fixative ${ }^{9}$ supplemented with $0.2 \%$ Tween 20. Fixed and permeabilized cells were probed with a mouse anti- $\alpha$ SMA antibody (Sigma, Cat.\# A2547; 1:100 dilutions) and a secondary antimouse-Alexa Fluor 488 antibody (Molecular Probes, Cat.\# A-21202; 1:200 dilutions) and with rhodamine-conjugated phalloidin (Molecular Probes, Cat.\# R-415 $5 \mathrm{U} / \mathrm{ml} ; 20 \mathrm{U} / \mathrm{ml}$ ). The total number of cells (phalloidin stained) and $\alpha$ SMA-negative cells were counted in eight randomly chosen fields $(\times 40$ magnification).

\section{(b) Sprouting from spheroids in fibrin gels}

The assay is based on a method described by Korff and Augustin ${ }^{12}$ for studies of endothelial cell sprouting from spheroids. Cells derived from sprouts growing from chicken aorta (see above) or primary human aortic smooth muscle cells (Clonetics, Cat.\# CC-2571, isolated from a 62-year-old female) were used. Trypsinized cells were suspended in Ham's F12 medium containing 20\% FBS and $0.2 \%$ methylcellulose. Droplets (1000 cells in $20 \mu \mathrm{l}$ ) were placed on the internal part of a lid to a bacterial dish. A volume of $5 \mathrm{ml}$ of sterile PBS was poured into the dish and the dish was then covered with the lid carrying approximately 80 hanging drops. Spheroids, which were formed after 2 days of incubation at $37^{\circ} \mathrm{C}$, were harvested in FBS-free Ham's F12 medium and resuspended in a fibrinogen solution prepared as described above. The fibrinogen solution $(0.5 \mathrm{ml}$; approximately 10 spheroids) was then poured on prepolymerized fibrin gels in a 24-well plate. After polymerization of this second layer, $1 \mathrm{ml}$ of Ham's F12 medium containing $0.2 \%$ BSA was added and explant cultures photographed after 7 days of incubation with or without $10 \mathrm{ng} / \mathrm{ml}$ FGF-2 or $10 \%$ serum as indicated. 


\section{(c) Immunoblotting}

Cells were placed on ice, washed with cold PBS and lysed with ice-cold lysis buffer (50 mM Tris $\mathrm{pH} 7.0$, $1 \%$ Triton X-100, 0.5\% Nonident P-40, $150 \mathrm{mM}$ $\mathrm{NaCl}, 15 \%$ glycerol, $0.1 \mathrm{mM} \mathrm{Na} \mathrm{VO}_{4}, 1 \mathrm{mM}$ EDTA, $1 \mathrm{mM}$ EGTA, $2 \mathrm{mM}$ phenylmethylsulfonylfluoride, $200 \mathrm{IU} / \mathrm{ml}$ aprotinin, $10 \mu \mathrm{g} / \mathrm{ml}$ leupeptin). Total cell lysates were transferred to microcentrifuge tubes containing SDS-PAGE sample buffer $(350 \mathrm{mM}$ Tris, $\mathrm{pH}$ 6.8, 10\% SDS, 25\% $\beta$-mercaptoethanol, $10 \mathrm{mg} /$ $\mathrm{ml}$ bromophenol blue). Samples were boiled for $7 \mathrm{~min}$ at $99^{\circ} \mathrm{C}$ and proteins resolved by SDS-PAGE and transferred to a nitrocellulose membrane. The membrane was blocked for $1 \mathrm{~h}$ with $5 \%$ BSA in Trisbuffered saline containing $0.1 \%$ Tween 20 and probed with the mouse anti- $\alpha$ SMA antibody (1:3000 dilutions) overnight at $4^{\circ} \mathrm{C}$. Protein bands were visualized using a horseradish peroxidaseconjugated rabbit anti-mouse IgG antibody in combination with a commercial ECL kit (Amersham). Membrane-bound antibodies were then stripped for $30 \mathrm{~min}$ at $55^{\circ} \mathrm{C}$ in $10 \% \beta$-mercaptoethanol, $2 \%$ SDS in TBS, blocked again with 5\% BSA and reprobed with a goat anti-total actin antibody to control for equal loading (Santa Cruz, Cat.\# sc-1615; 1:500 dilution). This was followed by incubation with a horseradish peroxidase-conjugated horse anti-goat IgG antibody and bands were visualized with the ECL kit.

\section{Immunohistochemistry}

Freshly isolated aortic arteries and fibrin-embedded aortic tissue explants stimulated with FGF-2 for 6 days were fixed in a $\mathrm{Zn}$-fixative for $24 \mathrm{~h}$ and then subjected to standard paraffin-embedding and sectioning as described by Beckstead. ${ }^{9}$ Briefly, routine $5-\mu \mathrm{m}$ sections were cut, deparaffinized and blocked in NEL blocking buffer according to instructions supplied by the manufacturer (Perkin Elmer, tyramide signal amplification, Cat.\# NEL700). Slides were then probed with a mouse anti- $\alpha$ SMA antibody (1:5000 dilutions), a rabbit anti-desmin antibody (Chemicon, Cat.\# AB907; 1:20 dilution) or $10 \mu \mathrm{g} / \mathrm{ml}$ biotinylated Sambucus nigra lectin (Vector Laboratories, Cat.\# B-1305) supplemented with $5 \mathrm{mM} \mathrm{CaCl}_{2}$ and $10 \mathrm{mM} \mathrm{MgCl}_{2}$. Biotinylated rabbit anti-mouse (Vector Laboratories, Cat.\# K0303; 1:200 dilutions) or goat anti-rabbit (Vector Laboratories, Cat.\# BA1000; 1:200 dilutions) antibodies were applied before slides were incubated with $20 \mu \mathrm{g} / \mathrm{ml}$ of avidin-peroxidase and signal detected using $400 \mathrm{ng} / \mathrm{ml} \mathrm{DAB}, 6 \mathrm{mg} / \mathrm{ml} \mathrm{NiSO}{ }_{4}$ and $0.03 \% \mathrm{H}_{2} \mathrm{O}_{2}$ in TBS.

\section{Visualization of Three-Dimensional Sprouting and Statistical Analysis}

A number of photographs of the gels with aortic tissues and growing sprouts were taken along the $Z$ - axis with approximately $50 \mu \mathrm{m}$ manual steps under constant magnification. The function 'best focus' provided by the Photoshop CS (Adobe Systems Inc.) plug-in IPTK (Reindeer Graphics, Ashville, TN, USA) was used to assemble one sharp image by adding the sharpest details from the individual photographs. The resulting image flattens the threedimensional outgrowth of sprouts and includes only structures that were in focus on different sample depths. The sprouting responses were quantified using a technique similar to what was reported by $\mathrm{Ng}$ et al. ${ }^{13}$ The total area occupied by sprouts on photographs taken with the same magnification and resolution was used as a representation of the sprouting response. The difference in sprouting between FGF-2-stimulated and control explants was determined using a two-sampled $t$-test assuming equal variation. The influence of tissue size on sprouting was analyzed by plotting the area occupied by sprouts against the explant area followed by fitting the linear regression equation and calculating the coefficient of determination $r^{2}$. For stimulation with growth factors other than FGF-2, a YES or NO scoring method was used. Experiments in the scored groups were performed in triplicates and repeated at least twice.

\section{Results}

\section{Myofibroblasts Invade a Preformed Provisional Matrix of Fibrin/Collagen Placed on the Chicken CAM}

As an in vivo model of the invasive phenotype of myofibroblasts, we used an assay where FGF-2 stimulates vascularization of a preformed fibrin matrix placed on the CAM (Figure 1a). ${ }^{8}$ This model is characterized by contraction of the applied gel, which is subsequently replaced by a vascular tissue, similar to the process of coetaneous wound healing (Figure 1b). Immunohistochemical analysis of the ingrown granulation tissue showed elongated and interconnected $\alpha$ SMA-positive (Figure 1c) but desmin-negative (Figure 1d) myofibroblasts growing from the CAM surface.

\section{Aortic Arteries are a Pure Source of Vascular Smooth Muscle Cells}

In order to develop an ex vivo model for studies of invasive growth of myofibroblasts, we used aortic tissue from developing chickens. The reason for selecting this tissue was that this is a relatively pure source of VSMCs and fibroblasts, which are cells capable of differentiating into myofibroblasts. ${ }^{4}$ The CAM itself was not used since it contains a large number of endothelial cells that have been shown to form cellular sprouts when embedded in fibrin matrices. However, aortic explants have also been used to study endothelial cell sprouting and it was 

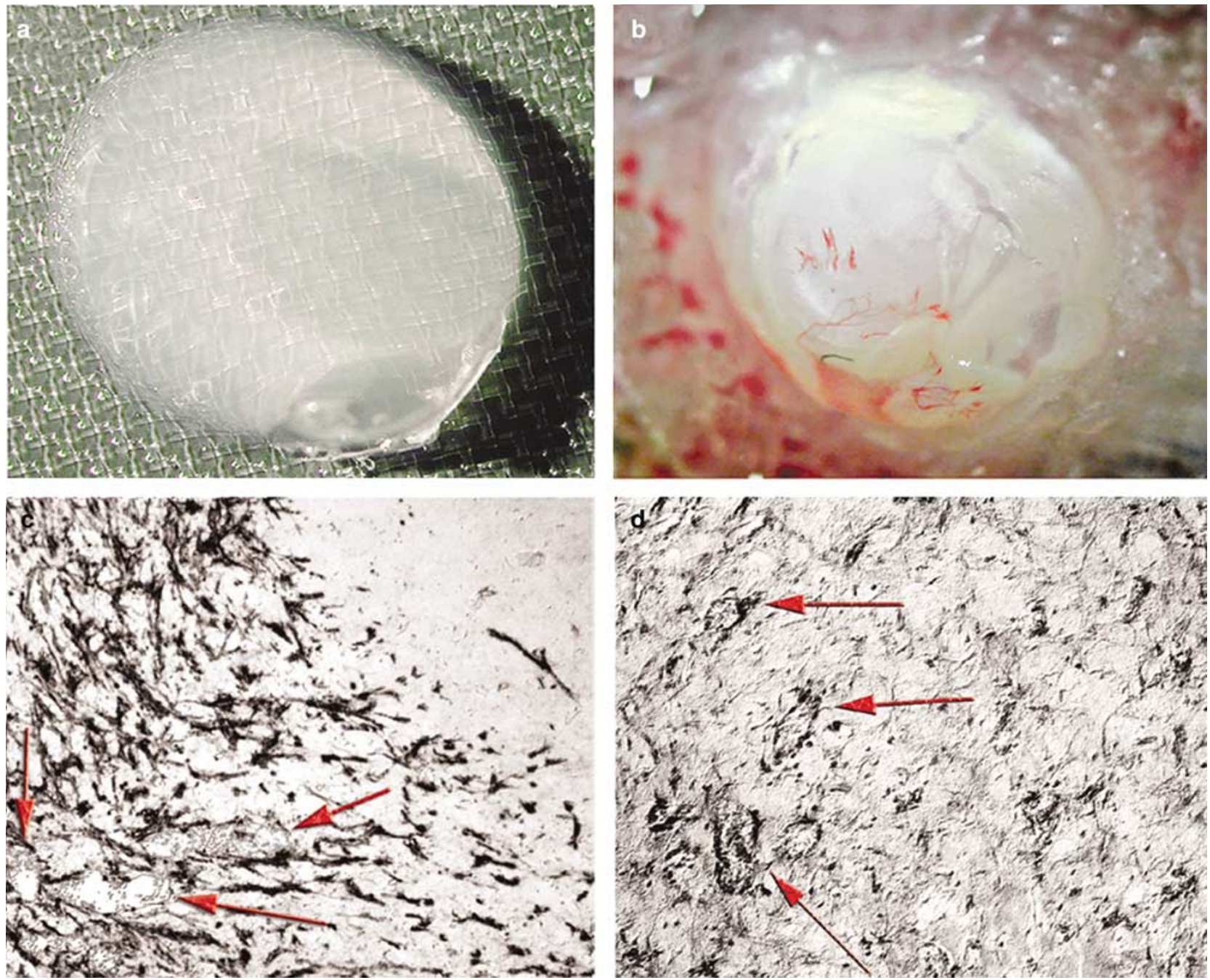

Figure 1 Formation of granulation tissue on the CAM. (a) A provisional matrix of fibrin and collagen I was formed on a nylon grid. The construct was applied on a 13-day-old chicken CAM and incubated for 6 days. (b) During the incubation, the fibrin/collagen gel contracted and there was an ingrowth of a vascular tissue into the matrix. Immunohistochemical analysis of a section at the interface between the gel and the invading granulation tissue showed that (c) $\alpha$ SMA-positive but (d) desmin-negative cells preceded blood vessel ingrowth (arrows point at vessels).

therefore important to determine the endothelial content in embryonic chicken arteries. This was done indirectly by assessment of the capillary content since capillaries would be a potential source of endothelial cells. The vascular network was visualized by intravenous injection of ink (colloidal carbon), which was distributed to all blood vessels in the entire chicken (not shown). The threedimensional structure of vascular networks was visualized by clarification of tissues with BBBA. This procedure makes tissues transparent while the light absorbance of the carbon is not affected. Figure 2 illustrates the dramatic increase in visibility of the vasculature in the heart before (a, c) and after (b, d) treatment with BBBA. While a high density of capillaries was found in the heart, the embryonic chicken aortic wall was largely devoid of vessels. The only possible sources of endothelial cells were hence restricted to one cell layer of tunica intima and small vessels in the tunica adventitia. However, the latter was removed by dissection before embedding explants in fibrin (Figure 1e). The same figure

Figure 2 Visualization of tissue vasculature (a, c) The vasculature of a 15-day-old chicken was injected with ink and the heart with its five main arteries removed by dissection and photographed. (b, d) Then, tissues were dehydrated in a graded series of alcohol, made transparent by treatment with BBBA to visualize the tissue vasculature and the same areas photographed again. Panels (c) and (d) are magnifications of one of the arteries leaving the heart. The arrows in (c) and (d) point to a vessel of the vasa vasorum of the tunica adventitia. In (b) and (d), the ink-filled dark lumens of the main arteries leaving the heart are seen. (e) The reciprocal localization of arteries that were cleaned from vasculature of the vasa vasorum and used in this study. Photographs were taken with a $\times 35$ magnification in (a, b) and $\times 20$ in (e). 

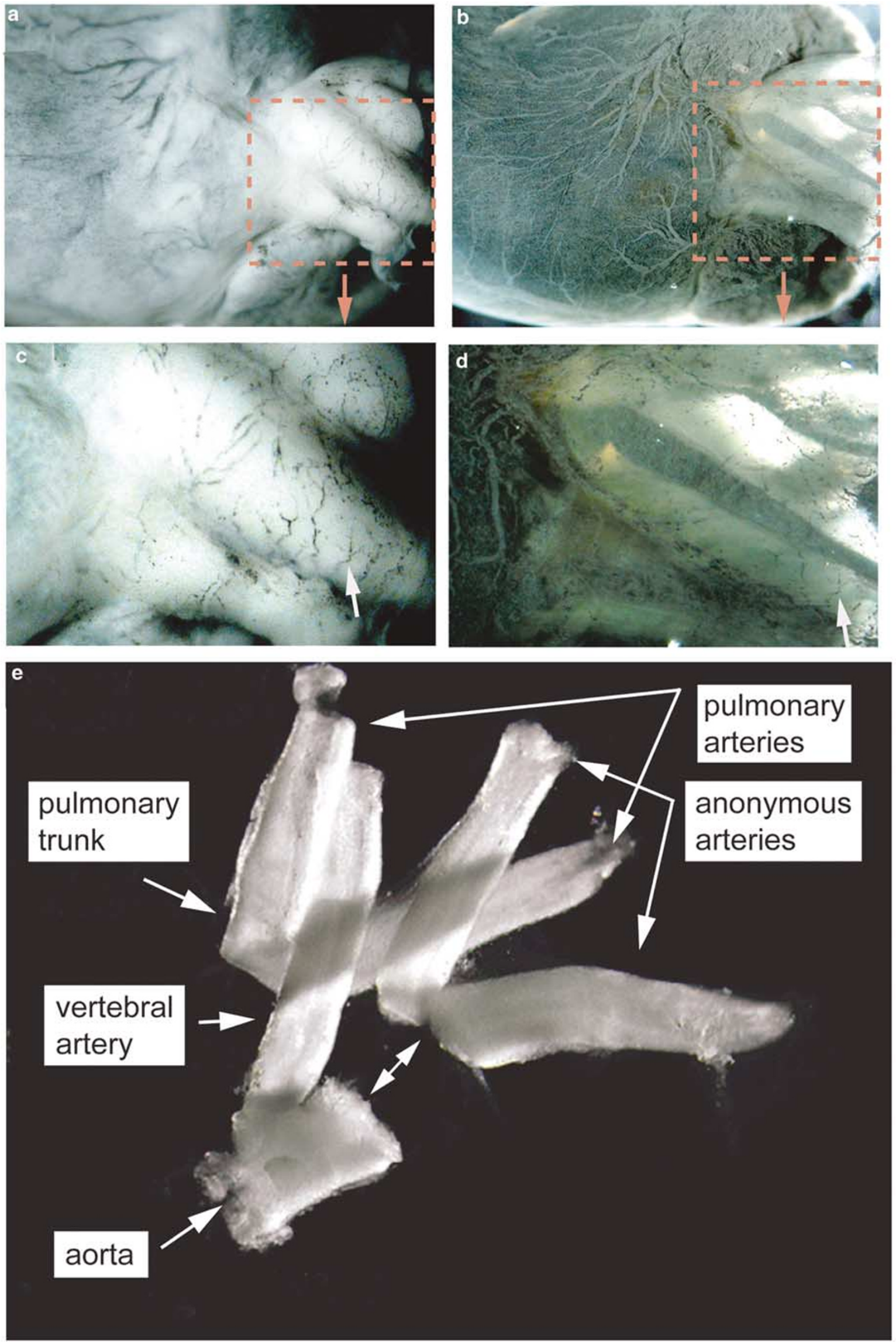
depicts the names and the reciprocal localizations of the large elastic vessels, which were used in this study.

\section{Serum, FGF-2 and PDGF-BB, but not VEGF, Stimulate Sprouting from Aortic Explants}

Culture of fibrin-embedded aortic explants in the presence of FGF-2 (Figure 3b), PDGF-BB (Figure 3d) or $10 \%$ bovine calf serum (not shown) induced a significant increase in formation of branching sprouts $(P<0.0001$ for FGF-2-stimulated cultures). In contrast, VEGF-A (Figure 3c), EGF, TNF $\alpha$ or P1GF (not shown) did not stimulate sprouting. Since the explants varied in size, we studied the effect of their size on sprouting by plotting the areas occupied by sprouts and correlated these to the size of the explants (delineated in Figure 3a,b). There was a correlation between explant size and the sprouting response in nonstimulated cultures $\left(r^{2}=0.403\right.$; $P<0.05$; Figure 3e), while the FGF-2-stimulated sprouting was independent of explant size $\left(r^{2}=0.001, P<0.84\right.$; Figure 3e). FGF-2 stimulation resulted in an 8-time larger sprout area, when compared to control samples $(P<0.0001)$.

\section{Sprouting Cells are $\alpha$ SMA-Positive but Desmin-Negative}

Intact 15-day old chicken embryos were fixed in a Zn-fixative and sections stained with an anti- $\alpha$ SMA antibody (Figure 4a). Aortic arteries consisted of $\alpha$ SMA-positive cells arranged in multiple concentric layers with $\alpha$ SMA-negative tissue layers in between. Similar concentric structures were found in aortic rings embedded and cultured in fibrin for 7 days (Figure 4c). Despite the existence of $\alpha$ SMA-negative tissue layers, a majority of the sprouting cells were found to be $\alpha$ SMA-positive (Figure 4c) as previously described. ${ }^{14}$ The $S$. nigra lectin is a marker of chicken endothelial cells ${ }^{15}$ that stained only the endothelial lining of the tunica intima and capillaries from vasa vasorum of the tunica adventitia (Figure 4b). No endothelial cells were identified in the thick multilayered wall of tunica media or in FGF-2-stimulated sprouts invading the fibrin gel (Figure 4b,d). Vascular smooth muscle cells were distinguished from differentiated myofibroblasts by staining for desmin, a muscle intermediate filament. Desmin is strongly expressed by cells of normal smooth, skeletal and cardiac muscles but not expressed or weakly so in mature myofibroblasts. ${ }^{16}$
In agreement with this, in the CAM-based wound healing model, desmin-positive cells were found in the media of ingrown macrovessels while the elongated and interconnected interstitial cells were desmin-negative (Figure 1d). Similarly, cells in the aortic fragment embedded in the fibrin remained desmin-positive, while cells invading the fibrin gel were desmin-negative (Figure 4e). We found that fibrin-embedded fragments of the CAM, connective tissue (tunica adventitia) and heart muscle produced cellular sprouts composed of $\alpha$ SMA-positive and desmin-negative myofibroblasts (not shown). Desmin-positive and $\alpha$ SMA-negative sprouts were found emerging from skeletal muscle explants (Figure 4f). These sprouts were less branched, thicker and had a more uniform thickness compared to myofibroblast sprouts. These desmin-positive structures might represent induced and differentiating muscle stem cells normally responsible for heart and skeletal muscle regeneration. ${ }^{17}$

To characterize the nature of sprouting cells, we removed the explants from cultures with forceps and trypsinized the remaining gel with sprouts to isolate cells that were then briefly (one passage) cultured. Analysis of fixed cells showed that out of 219 cells (stained for total F-actin), only $8(3.7 \%)$ were found to be $\alpha$ SMA-negative (Figure $5 \mathrm{c}, \mathrm{d}$ ). The high level of cell-type homogeneity in sproutderived cells was confirmed by Western blot analysis (Figure 5g). Total $\alpha$ SMA content in sproutderived cells was equal to that found in a mouse smooth muscle cell line. To ensure that the isolated cells did not change their sprouting phenotype during culture, spheroids were made from sproutderived cells by culture of cells in methocel as hanging drops for 2 days. Under these conditions, cells aggregated and formed spheroid bodies, which were then re-embedded in fibrin. Sprouting was observed already after $12 \mathrm{~h}$ of culture, but in contrast to sprouting from aortic tissue, it was growth factorindependent (Figure 5b). Sprouts from aortic explants were morphologically indistinguishable from sprouts originating from spheroids (Figure 5a,b). Finally, we demonstrated that vascular smooth muscle cells have the ability to form branching cellular sprouts by preparing spheroids of purified primary human aortic smooth muscle cells that were then embedded in fibrin. Outgrowth of sprouts could be observed after 7 days of incubation (Figure $5 e)$ and addition of $10 \%$ serum further enhanced the response (Figure 5f). Similar but less organized (poorly interconnected) sprouts were observed

\footnotetext{
Figure 3 FGF and PDGF but not VEGF-A stimulate sprouting from aortic tissue. Pieces of arteries were embedded in fibrin gels and cultured in the presence of (a) vehicle, (b) $20 \mathrm{ng} / \mathrm{ml} \mathrm{FGF-2,} \mathrm{(c)} 200 \mathrm{ng} / \mathrm{ml}$ VEGF-A or (d) $20 \mathrm{ng} / \mathrm{ml}$ PDGF-BB. After 7 days, multiple photographs were taken at different focus levels and sharp images assembled (see Materials and methods). FGF-2 and PDGF-BB induced sprouting while VEGF-A did not. For quantification, the explant areas (the inner lines in (a) and (b)) were subtracted from the total areas including both explants and sprouts (the outer lines in (a) and (b)). (e) Values for control (black diamonds) and FGF-2-stimulated groups (open squares) were plotted against the size of the corresponding explant areas (inner lines in (a) and (b)). Linear regressions were fit to each group and the correlation coefficients $r^{2}$ were calculated. Experiments with PDGF-BB and VEGF-A were repeated three times in triplicates and scored in a double-blinded manner. Magnification: $\times 10$.
} 
a

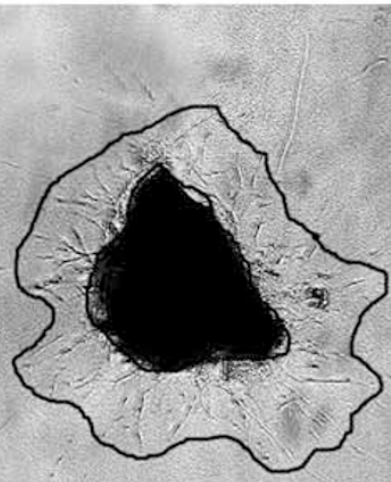

Ctrl

c

VEGF b

\section{FGF-2}

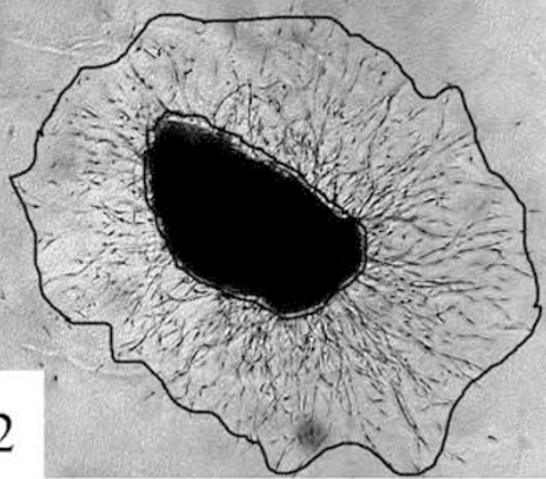

d

PDGF

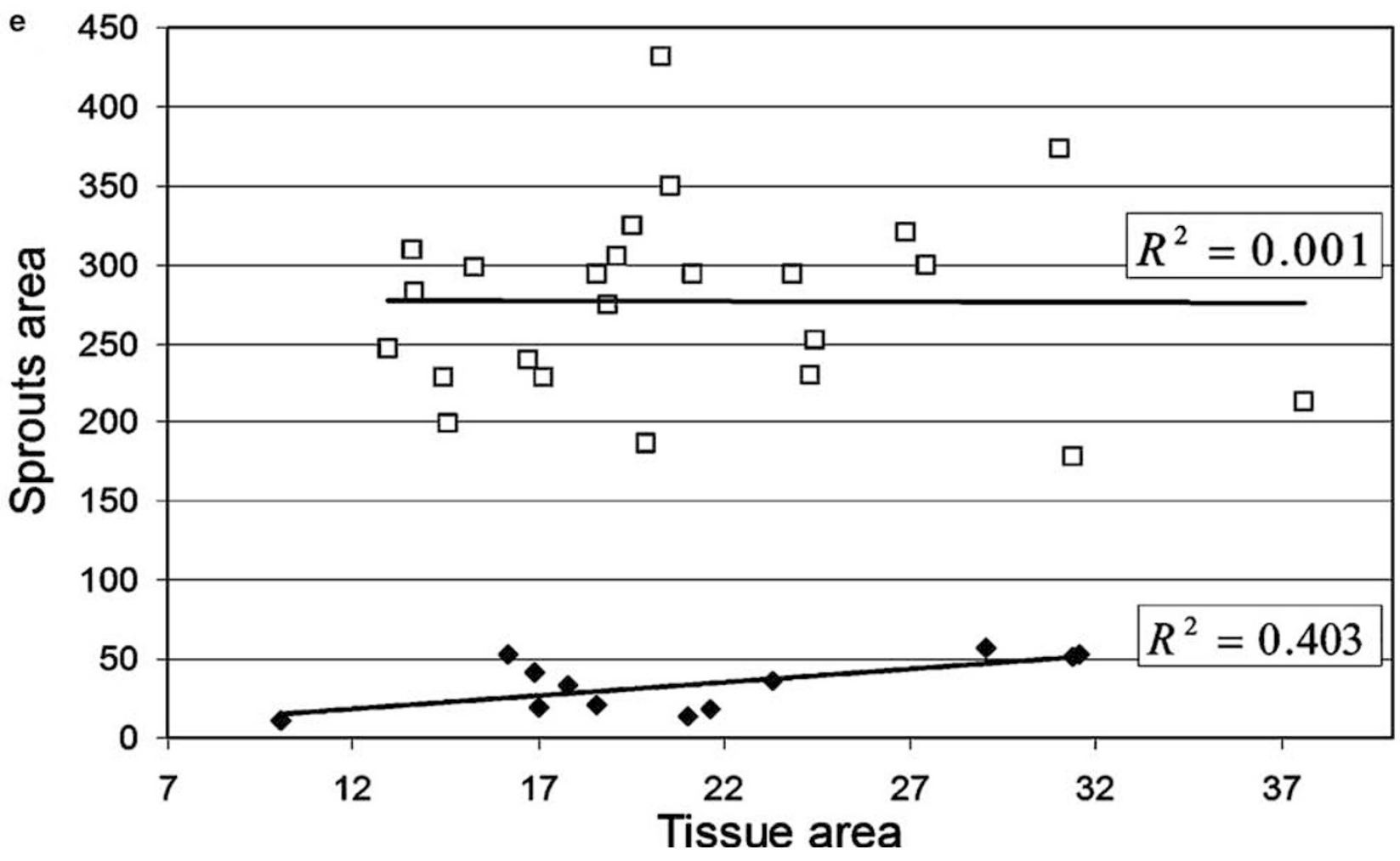



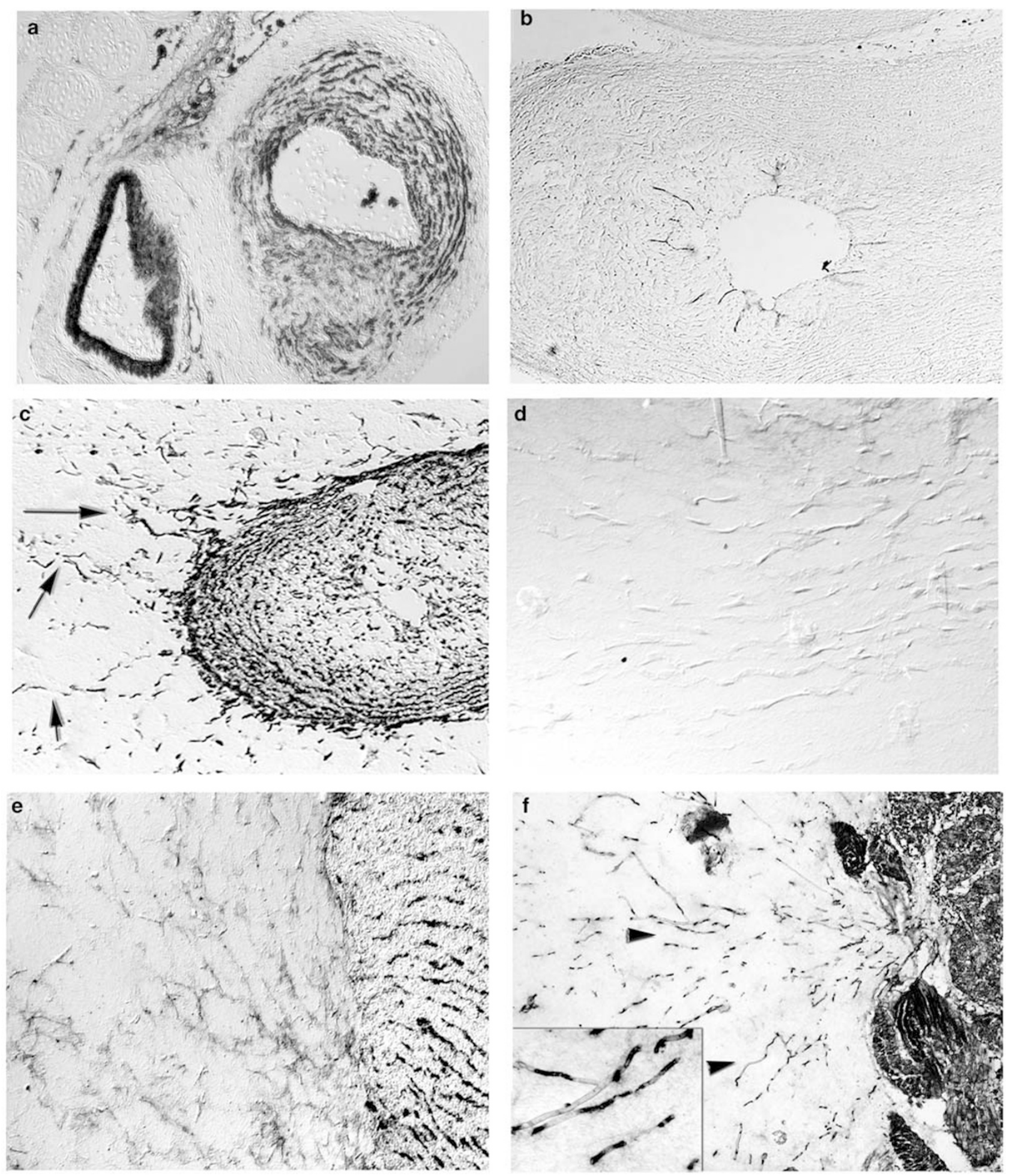

Figure 4 Sprouting cells are SMA-positive but desmin- and S. nigra lectin-negative (a) A 15-day-old chicken embryo, (b) isolated arteries and (c, d) chicken aortic explants cultured in a fibrin matrix with FGF-2 for 7 days were Zn-fixed and subjected to standard paraffin embedding and sectioning. The large vein of the heart is composed of a dense $\alpha$ SMA-positive tissue (to the left in (a)) while in the aorta $\alpha$ SMA-positive lamellas are interleaved by elastic tissue with fibrocytes (to the right in (a)). (b) Staining of chicken endothelium with the $S$. nigra lectin showed that the endothelial pool was limited to the intima layer. In contrast to total embryo sections (a), the arteries dissected from the embryo prior incubation or fixation $(\mathbf{b}, \mathbf{c})$ showed an irregular pattern with lumen invaginations. This was due to lumen collapse caused by release of vessel wall tension. Sprouts originating from an aortic ring were $\alpha$ SMA-positive (arrows in (c)). There were no endothelial cells in sprouts as detected with the $S$. nigra lectin (d). (e) Vascular smooth muscle cells were distinguished from differentiated myofibroblasts by staining for desmin. Cells in the aortic fragment embedded in the fibrin remained desmin-positive while cells invading the fibrin gel were desmin-negative. (f) In contrast, desmin-positive and $\alpha$ SMA-negative (not shown) sprouts were found emerging from skeletal muscle explants. Magnifications: (a) $\times 100$, (b, c) $\times 200$, (d, e) $\times 400$. 
when a conditionally immortalized mouse vascular smooth muscle cell line (IBSMC) ${ }^{18}$ was used (not shown).

\section{Discussion}

Classical in vitro models that are used to study differentiation of fibroblasts into myofibroblasts focus on the potential of cells to contract collagen or develop mechanical tension in tethered collagen lattices. ${ }^{2}$ The assay described in this report allows studies of proliferation, migration and invasive growth of myofibroblasts derived from arterial fibrocytes/VSMCs in a three-dimensional fibrin matrix. Even though we found that other tissues could produce myofibroblastic sprouts when embedded in fibrin, the use of arterial tissue provided a pure source of smooth muscle cells/fibroblasts without contamination with blood-borne components and endothelial cells that are present in the capillary network of the other tissues. In addition, the uniform structure of elastic arteries ensured reproducible results. The cellular organization of sprouts growing from arterial explants resembled the histological organization of myofibroblast invading a provisional matrix in vivo where $\alpha$ SMApositive cells grew as polarized and interconnected units. Similar to cutaneous wound healing, invasion of myofibroblasts was followed by contraction and ingrowth of vascular granulation tissue into the matrix. ${ }^{19}$ We used fibrin matrix since it is a physiologically relevant provisional scaffold that supports cells during tissue repair, tumor growth and neovascularization and its formation is naturally followed by remodeling processes. ${ }^{20,21}$ In addition, vascular diseases like arteriosclerosis and restenosis are characterized by deposition of fibrin in the vascular wall that is followed by invasion and proliferation of VSMCs. ${ }^{22}$

Although there are reports where $\alpha$ SMA-positive cells are found in the proximity of sprouting endothelial cells, ${ }^{23,24}$ a majority of articles published to date describe the aortic sprouts as solely endothelial structures. ${ }^{11,25,26}$ In contrast, it has been estimated that less than $1 \%$ of the cells in human embryonic aorta are endothelial cells. ${ }^{27}$ Since aortic tissue is a relatively pure source of VSMCs, and has the lowest ratio of endothelium to VSMCs in the vertebrate body, ${ }^{28,29}$ it is surprising that sprouting $\alpha$ SMA-positive cells have not attracted more attention. Nonetheless, the endothelium is known for its sprouting capabilities ${ }^{30}$ and there was a possibility that traces of endothelial cells from the capillary of tunica adventitia might contribute to formation of sprouts. The degree of vascularization of the tunica media by the vasa vasorum may also vary between species and depend on animal age. ${ }^{31}$ To characterize vascular networks within the elastic arteries of chicken embryos, we improved a technique for staining vessels with colloidal carbon (India ink). ${ }^{10}$
Organs with ink-perfused vasculature were made transparent by clarification with BBBA, which enabled visualization of ink-filled vessels. These experiments confirmed that the thickest layer of the arterial wall, the tunica media, was avascular and that the endothelial compartment was limited to the arterial luminal side and to small vessels and capillaries in the tunica adventitia. Therefore, to minimize the contamination of endothelial cells, blood-borne cells and growth factors, the adventitia was routinely removed before embedding explants in fibrin. Indeed, when sprouting cells were analyzed, more than $95 \%$ stained positive for $\alpha \mathrm{SMA}$. Furthermore, sprouting was induced by FGF-2 and PDGF-BB, which are known to stimulate proliferation and migration of VSMCs and myofibroblasts, ${ }^{32}$ while the endothelial cell-specific growth factor VEGF-A had no effect. The ability of vascular smooth muscle cells to form cellular sprouts was further characterized by using primary human vascular smooth muscle cells. In contrast to cells isolated from sprouting chicken aortic tissue, primary human cells required addition of serum for maximal sprouting. This might be related to differences between embryonic chicken cells and adult primary human cells or by changes caused by invasive growth in fibrin before isolation of chicken cells. Sprouting, the interconnected branching growth of cells in three-dimensional matrices, is hence not limited to endothelial cells when using aortic tissue but also characterizes myofibroblasts.

We introduced a technique for presenting threedimensional sprouting structures on one sharp image that circumvents the problematic use of lowpowered magnification ${ }^{33}$ in bright-field microscopy to achieve a deep focus along the $Z$-axis. We found that the degree of sprouting was dependent on explant size only when the aortic tissue was cultured without addition of growth factors. This might be due to the release of intrinsic growth factors such as FGF-2 after dissection of the aortic arteries as suggested by Villaschi and Nicosia. ${ }^{34}$ However, explant size had no influence on FGF-2stimulated cultures.

The method described in this report allows studies of myofibroblast differentiation and matrix invasiveness and can be complementary to known in vitro models design to study myofibroblastdependent force generation in three-dimensional matrices. Since myofibroblasts are essential components during wound healing and the development of a variety of diseases such as cancer, cardiovascular disorder and fibrosis, this model system might be useful in finding both enhancers and inhibitors of these processes that can be used as therapeutic agents.

\section{Acknowledgements}

We are grateful to Professor Lena Claesson-Welsh for helpful discussions and for critically reading 

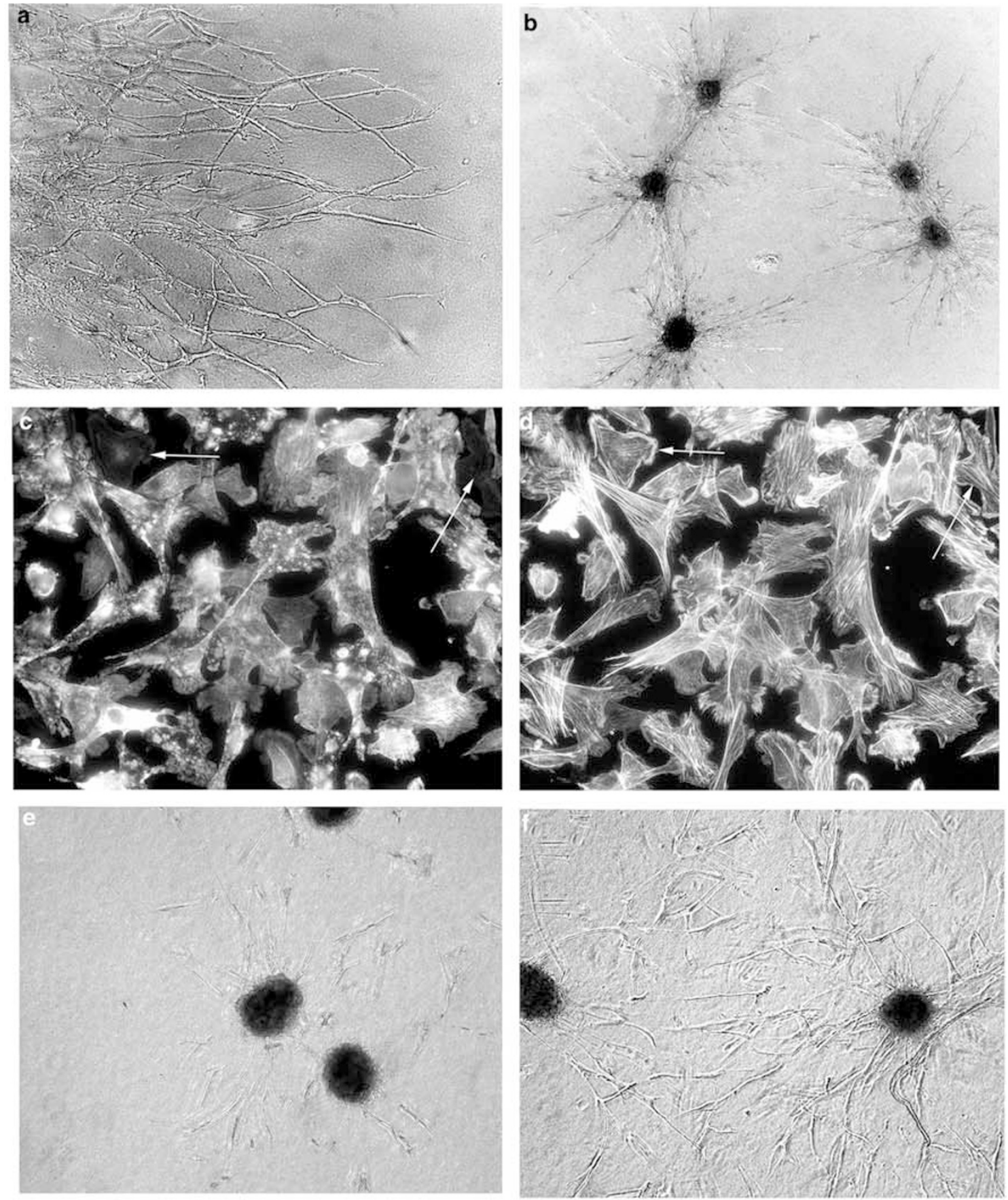

g

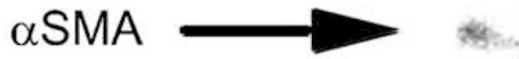

nolonenowist:
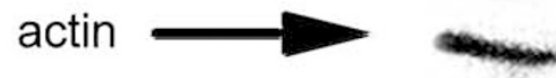

PAE SC IBEC IBSMC 
Figure 5 Sprout-derived cells (SC) express $\alpha$ SMA and resume gel invasion when re-embedded in fibrin. (a) Sprouting cells from aortic explants cultured with FGF-2 for 7 days were isolated as described in Materials and methods and then cultured on a plastic dish as SC. Cells were harvested and then used to form spheroid bodies (b), plated on glass slides for immunocytochemistry (c, d) or lysed and analyzed by Western blotting (g). Spheroids were embedded in fibrin and cultured under serumfree conditions for 7 days. SC resumed sprouting after $12 \mathrm{~h}$ and the structure of these was similar to the original aortic sprouts (compare (b) with (a) and with Figure 3). (c) SC plated on glass slides were stained for $\alpha \mathrm{SMA}$ and (d) costained for F-actin with a phalloidin-rhodamine conjugate to reveal the total cell number. Less than $4 \%$ of cells were $\alpha$ SMA-negative (arrows). (e) Spheroids composed of purified primary human aortic smooth muscle cells were embedded in fibrin and cultured under serum-free conditions for 7 days. (f) Addition of $10 \%$ serum further enhanced the sprouting phenotype of primary human aortic smooth muscle cells. (g) Western blot analysis of $\alpha \mathrm{SMA}$ in lysates from porcine aortic endothelial cells (PAE), SC, immortalized mouse brain endothelial cells (IBEC) and immortalized mouse smooth muscle cells (IBSMC) showed that SDC and IBSMC express comparable levels of $\alpha \mathrm{SMA}$ while expression of this antigen remains on basal levels in two nonrelated endothelial cell lines (PAE and IBEC).

the manuscript. This work was supported by the Swedish Cancer Foundation (Project 4422-B04O5XAB), the Swedish Research Council (Project K2005-31X-15348-01A), the Children's Cancer Foundation of Sweden (Project 04/037), Lions Cancer Research Foundation in Uppsala, the Swedish Heart Lung Foundation, the Magn. Bergvall Foundation, King Gustaf the V:s 80 Year Foundation and the Linné Foundation for Medical Research in Uppsala.

\section{Competing interest's statement}

None of the authors has any competing interests.

\section{References}

1 Gabbiani G, Ryan GB, Majne G. Presence of modified fibroblasts in granulation tissue and their possible role in wound contraction. Experientia 1971;27:549-550.

2 Tomasek JJ, Gabbiani G, Hinz B, et al. Myofibroblasts and mechano-regulation of connective tissue remodelling. Nat Rev Mol Cell Biol 2002;3:349-363.

3 Gabbiani G. The myofibroblast in wound healing and fibrocontractive diseases. J Pathol 2003;200:500-503.

4 Shi Y, O’Brien JE, Fard A, et al. Adventitial myofibroblasts contribute to neointimal formation in injured porcine coronary arteries. Circulation 1996;94:1655-1664.

5 Jester JV, Huang J, Petroll WM, et al. TGFbeta induced myofibroblast differentiation of rabbit keratocytes requires synergistic TGFbeta, PDGF and integrin signaling. Exp Eye Res 2002;75:645-657.

6 Heughan C, Niinikoski J, Hunt TK. Atherosclerosis and healing. In: Hunt TK (ed). Wound Healing and Wound Infection. Theory and Surgical Practise. AppletonCentury-Crofts: New York, 1980, pp 72-80.

7 De Wever O, Mareel M. Role of myofibroblasts at the invasion front. Biol Chem 2002;383:55-67.
8 Kilarski WW, Jura N, Gerwins P. Inactivation of Src family kinases inhibits angiogenesis in vivo: implications for a mechanism involving organization of the actin cytoskeleton. Exp Cell Res 2003;291:70-82.

9 Beckstead JH. A simple technique for preservation of fixation-sensitive antigens in paraffin-embedded tissues. J Histochem Cytochem 1994;42:1127-1134.

10 Paschold $K$. The behavior of the vasa vasorum in the new formation of the blood vessel wall following implantation of alloplastic blood vessel prosthesis. Experimental studies with India ink injections according to Staubesand. Langenbecks Arch Chir 1966; 314:231-245.

11 Nicosia RF, Ottinetti A. Growth of microvessels in serum-free matrix culture of rat aorta. A quantitative assay of angiogenesis in vitro. Lab Invest 1990;63: 115-122.

12 Korff T, Augustin HG. Integration of endothelial cells in multicellular spheroids prevents apoptosis and induces differentiation. J Cell Biol 1998;143:13411352.

13 Ng SS, Gutschow M, Weiss M, et al. Antiangiogenic activity of N-substituted and tetrafluorinated thalidomide analogues. Cancer Res 2003;63:3189-3194.

14 Yablonka-Reuveni Z, Christ B, Benson JM. Transitions in cell organization and in expression of contractile and extracellular matrix proteins during development of chicken aortic smooth muscle: evidence for a complex spatial and temporal differentiation program. Anat Embryol (Berl) 1998;197:421-437.

15 Nanka O, Peumans WJ, Van Damme EJ, et al. Lectin histochemistry of microvascular endothelium in chick and quail musculature. Anat Embryol (Berl) 2001;204: 407-411.

16 Fisher C. Myofibrosarcoma. Virchows Arch 2004;445: 215-223.

17 Bick-Forrester J, Lee MS, Makkar RR, et al. Partial restoration of myocardial function and perfusion by cell therapy following myocardial infarction. Curr Opin Cardiol 2004;19:631-637.

18 Ehler E, Jat PS, Noble MD, et al. Vascular smooth muscle cells of $\mathrm{H}-2 \mathrm{~Kb}$-tsA58 transgenic mice. Characterization of cell lines with distinct properties. Circulation 1995;92:3289-3296.

19 Diegelmann RF, Evans MC. Wound healing: an overview of acute, fibrotic and delayed healing. Front Biosci 2004;9:283-289.

$20 \mathrm{Li} \mathrm{J}$, Zhang YP, Kirsner RS. Angiogenesis in wound repair: angiogenic growth factors and the extracellular matrix. Microsc Res Techn 2003;60:107-114.

21 Nagy JA, Brown LF, Senger DR, et al. Pathogenesis of tumor stroma generation: a critical role for leaky blood vessels and fibrin deposition. Biochim Biophys Acta 1989;948:305-326.

22 Kodama M, Naito M, Nomura $\mathrm{H}$, et al. Role of D and $\mathrm{E}$ domains in the migration of vascular smooth muscle cells into fibrin gels. Life Sci 2002;71:1139-1148.

23 Nicosia RF, Ottinetti A. Modulation of microvascular growth and morphogenesis by reconstituted basement membrane gel in three-dimensional cultures of rat aorta: a comparative study of angiogenesis in matrigel, collagen, fibrin, and plasma clot. In Vitro Cell Dev Biol 1990;26:119-128.

24 Gerhardt H, Golding M, Fruttiger M, et al. VEGF guides angiogenic sprouting utilizing endothelial tip cell filopodia. J Cell Biol 2003;161:1163-1177. 
25 Malinda KM, Nomizu M, Chung M, et al. Identification of laminin alpha1 and beta1 chain peptides active for endothelial cell adhesion, tube formation, and aortic sprouting. FASEB J 1999;13:53-62.

26 Grant DS, Williams TL, Zahaczewsky $\mathrm{M}$, et al. Comparison of antiangiogenic activities using paclitaxel (taxol) and docetaxel (taxotere). Int J Cancer 2003;104:121-129.

27 Alessandri G, Girelli M, Taccagni G, et al. Human vasculogenesis ex vivo: embryonal aorta as a tool for isolation of endothelial cell progenitors. Lab Invest 2001;81:875-885.

28 Bloom W, Fawcett DW. Elastic arteries. In: Fawcett DW (ed). A Textbook of Histology. Chapman \& Hall: London, 1994.

29 Heistad DD, Marcus ML. Role of vasa vasorum in nourishment of the aorta. Blood Vessels 1979;16: 225-238.
30 Risau W. Mechanisms of angiogenesis. Nature 1997;386:671-674.

31 Phillips GD, Stone AM, Schultz JC, et al. Age-related alterations in the morphology of femoral artery vasa vasorum in the rat. Mech Ageing Dev 1995;82:149-154.

32 Powell DW, Mifflin RC, Valentich JD, et al. Myofibroblasts. I. Paracrine cells important in health and disease. Am J Physiol 1999;277:C1-C9.

33 Nakatsu MN, Sainson RC, Aoto JN, et al. Angiogenic sprouting and capillary lumen formation modeled by human umbilical vein endothelial cells (HUVEC) in fibrin gels: the role of fibroblasts and angiopoietin-1. Microvasc Res 2003;66:102-112.

34 Villaschi S, Nicosia RF. Angiogenic role of endogenous basic fibroblast growth factor released by rat aorta after injury. Am J Pathol 1993;143:181-190. 